\title{
CYBERBULLYING: EVALUATING AN INSTRUCTIONAL APPLICATION FOR SAFEGUARDING VULNERABLE USERS ONLINE
}

\author{
Marian McDonnell, Breanna Coyle and Irene Connolly \\ Institute of Art, Design and Technology \\ Kill Avenue, Dun Laoghaire, Co. Dublin, Ireland
}

\begin{abstract}
Bullying is an aggressive act on a target that is not able to defend themselves easily. Cyberbullying is bullying, when perpetrated through technology online and is a major challenge for adolescents today. Despite the abundance of literature in the area of human-computer interaction (HCI), there is limited HCI research about users with intellectual disability. This research project further evaluates Let's Be Safe, an eLearning application in development at the Institute of Art, Design and Technology, Dublin. This application aims to educate young adults with intellectual disability about cyberbullying. Twenty-two individuals with mild to moderate intellectual disability took part in the research. The evaluation investigated preferred learning modes and engagement for this user group. The study employed a mixed-methods design including observational and inquiry methods of usability evaluation. Adapted SUS self- report measures indicated that participants liked the Let's Be Safe application. The listening activity was most frequently the preferred learning modality, followed closely by the game activity. Indications are that participants would like to see more games and videos with people in the application. Observational analysis identified occurrences of positive and negative emotional engagement while using the Let's Be Safe application. Results revealed more positive emotional responses than negative emotional responses.
\end{abstract}

\section{KEYWORDS}

Bullying, Cyberbullying, Intellectual Disability, eLearning, Emotional Response, Usability

\section{INTRODUCTION}

\subsection{Bullying}

Bullying has been described as an aggressive act on a target that is not able to defend themselves easily (Smith, del Barrio, \& Tokunaga, 2013). Cyberbullying, perpetuated through technology, is a major challenge for adolescents today (Tokunaga, 2010). 20-40\% of youth have experienced cyberbullying, which is associated with academic and psychosocial problems (Tokunaga, 2010). While it is a responsibility of everyone to ensure safety, young people need to be empowered to stay safe online for themselves (Paine, 2009). Listening, empowering and supporting young people to manage risks will help them understand how to stay safe (Paine, 2009). The aim of this study is to evaluate a multiplatform educational intervention designed to empower people with intellectual disability (ID) to stay safe from traditional bullying in order to mitigate against the negative consequences and victimisation of cyberbullying.

\subsection{Defining Intellectual Disability (ID)}

An intellectual disability (ID) is defined by the American Association on Intellectual and Developmental Disabilities (AIDD), as a significant limitation of adaptive behaviour and intellectual functioning, originating before the age of 18 and is "expressed in conceptual, social and practical adaptive skills" (Schalock, Luckasson, \& Shogren, 2007, p. 118). Adaptive behaviour is a term that encompasses the impairments of ID in maturation, learning and social adjustment, as compared to peers (Heber, 1961). ID has replaced the term "mental retardation" frequently used in literature. The AIDD, the International Association have acknowledged ID as 
a term more appropriate in representing the construct of ID for the Scientific Study of Intellectual Disabilities, and the President's Committee for People with Intellectual Disabilities (Schalock, Luckasson, \& Shogren, 2007). ID focuses on the interaction of the person with the environment, i.e. the ecological dimension (Schalock, Luckasson, \& Shogren, 2007). The American Psychological Association (APA) guidelines require that the behaviour of an individual be assessed within context, to address the ecological approach (American Psychological Association, 2018). An ecological approach requires assessment of an individual by observation within natural settings, without intrusion and avoids interpretations based on norms (American Psychological Association, 2018). ID as a construct recognises "that the systematic application of individualized supports can enhance human functioning" (Schalock, Luckasson, \& Shogren, 2007, p. 117). Recognising and enhancing individual strengths has a positive impact on self-image and the ability to deal with life (Dunn \& Dougherty; Dykes, as cited in American Psychological Association, 2018). Interventions are required to support and encourage an individual to live their life to the fullest capacity, independently. The ID construct supports and recognises what is called the disability identity of the individual to include "self-worth, subjective well-being, pride, common cause, policy alternatives, and engagement in political action" (AIDD; Schalock; Vehmas; WHO, as cited in Schalock, Luckasson, \& Shogren, 2007, p.117). People with ID are increasingly being recognised for their own unique strengths (Shogren, et al., as cited in American Psychological Association, 2018). Designing an appropriate intervention for individuals with ID will not always take the form of the most explicit needs. Needs of an individual must be addressed without assuming treatment based purely on the diagnosed disability (Butz, Bowling, \& Bliss; Mason; Nezu \& Nezu, as cited in American Psychological Association, 2018). Interventions must be delivered within an established and secure working relationship. It must be based on an individual's life and disability related experiences. Educational psychology is required to consider the strengths along with the identified limitations of an individual with ID, assessing an individual within a context (American Psychological Association, 2018). Reframing identified difficulties is possible using a social paradigm to encourage a more collaborative relationship between the marginalised community of people with disabilities and the psychologist (Gill, Kewman, \& Brannon, 2003).

\subsection{Considering Human Computer Interaction (HCI) and User-Centred Design}

$\mathrm{HCI}$ is an academic discipline contributing to interaction design with a focus on "design, evaluation and implementation of interactive computing systems for human use" and the study of phenomena surrounding them (ACM SIGCHI, as cited in Rogers, Sharp, \& Preece, 2015, p.10). Interaction design is defined as "designing interactive products to support the way people communicate and interact" in their lives (Rogers, Sharp, \& Preece, 2015, p.8). This involves using theory and research to design user experiences within a specified context and directly relevant to the intended task. Within HCI development, the user-centred approach to development is emphasised (Rogers, Sharp, \& Preece, 2015). User centred design considers a system well designed when the real users and not the technology are the driving force in development. A well-designed system will support the user and work in a way that adheres to principles of identified human skills and judgements (Rogers, Sharp, \& Preece, 2015). Despite the abundance of literature in the area of human-computer interaction (HCI), there is limited HCI research about users with intellectual disability. This research project evaluates Let's Be Safe, an eLearning application in development at the Institute of Art, Design and Technology, Dun Laoghaire. This application aims to educate young adults with intellectual disability about cyberbullying

\subsection{Present Study}

Understanding our participants' needs and observing their interaction, within a user-centred approach, this evaluation of the web-based application Let's Be Safe will inform the iterative process of development of an appropriate instructional resource intervention to educate the user with ID. The aim is to design an accessible and user-friendly instructional resource to empower and educate about staying safe from bullying and cyberbullying. Using video modelling, picture-based interventions, game-based learning and scripts, through the web-based application Let's Be Safe, this study will explore the level of user engagement with the application and the preferred method of learning for participants with ID. 


\subsubsection{Research Questions}

1. Will adults with ID find the Let's Be Safe application engaging?

2. Will adults with ID find the Let's Be Safe application usable?

3. Will adults with ID, demonstrate a clear preference for a learning-modality provided in Let's Be Safe?

\section{METHOD}

\subsection{Design}

Advocacy research with marginalised groups needs to be approaches with more mixed methods approaches (Sweetman, Badiee, \& Creswell, 2010). Sensitivity within the qualitative approach is based on inquiry and values, with the ultimate goal of social justice (Denzin \& Lincoln, 2005). Mixed methods characteristics for participants with disability include focus groups to collect qualitative data and questionnaires in the collection of quantitative data (Boland, Daly, \& Staines, 2008). Mixing is seen within the results and discussion sections (Creswell, \& Creswell, 2017).A mixed methods design, using transformative theories, in the study of community health issues and marginalised groups has been growing. From a transformative perspective, identification of specific issues of a population, allows identification of issues for the group under investigation (Creswell, \& Creswell, 2017). A deeper level of understanding of the issues of this group has contributed to the research by the researchers' eight years of experience working with staff, parents and carers of people with ID, within a facilitative context. Bringing together a group of participants similar in their needs provides the opportunity to conduct a group interview (Coolican, 2004). Engagement in-group conversations stimulated by the questions offer an opportunity to provide insight that may not occur during a one-to-one interview and often provide a starting point for research (Coolican, 2004). Barrett and Kirk (2000) suggest smaller groups allow for the lived-experience of people with ID to come forward. A thematic analysis explored the themes in literature relating to the issues of this this group. Thematic analysis was conducted on the focus group answers based on themes identified in the research of this user group (vulnerability, safe guarding, issues of choice/self-determination, need for skill development).

Let's Be Safe is an eLearning application designed specifically for the use of individuals with intellectual disability. This application intends to educate young adults with intellectual disability about cyberbullying and cybersafety through video, animation, audio, reading and games. There are 6 modules in total: What is Bullying? Cyberbullying, Understanding Bystanders, Resilience, How to tackle Bullying, Respect and Empathy. Let's be Safe was designed for people with ID (see figure 1).
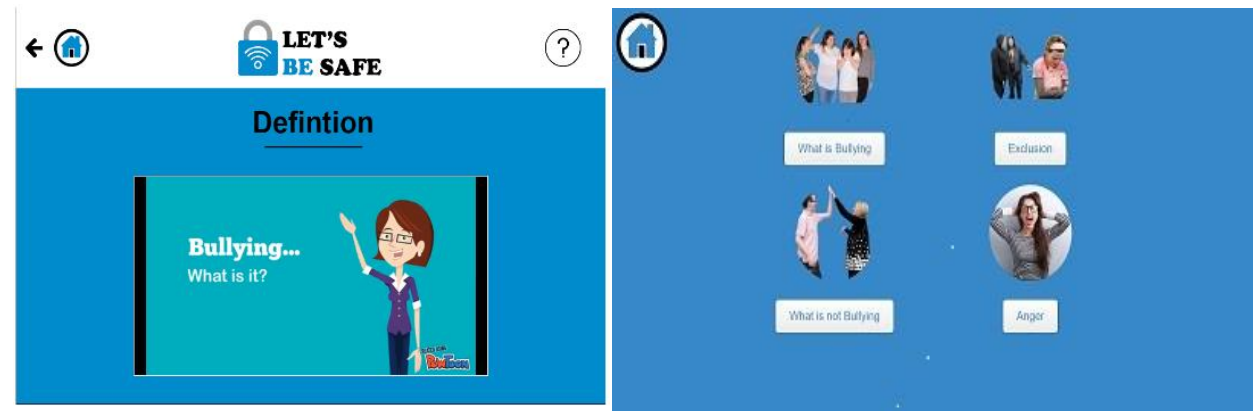

Figure 1. Let's be safe sample screenshots

Kirijian, Myers and Charland (2007) preferred design aspects for this user group were implemented in the final prototype. Fonts with bright colours and outlines were chosen, along with large words with heavy bold treatment. Colour choice was subjective, although nobody was in favour of dull colours. There was strong preference for inclusion of images. Images of young attractive people were included in particular, along with action images. More interest came from images of people of similar age. Animations of bright colour and in motion were included, especially if personalised. Buttons with a clear clickable area are included in the app design. Users like buttons that were very clear in telling what the user is to do. During the undisguised 
participant observation, participants are aware of being observed for the collection of information when using the application (Shaughnessy, Zechmeister, \& Zechmeister, 2003). Undisguised structured observations, were created through observations of interactions with the application Let's Be Safe (Shaughnessy, Zechmeister, \& Zechmeister, 2003). Observed instances of categorized behaviours, uses the frequency method of observation within a fixed time to convert observation into a numerical score (Gravetter, \& Forzano, 2012). Frequencies of observed behavioural and emotional responses to the learning application Let's Be Safe were recorded. While the contrived observational setting does not allow for a natural observation, it provides an opportunity to observe the behaviour without the need to wait for the occurrence (Shaughnessy, Zechmeister, $\&$ Zechmeister, 2003). A verbal summary, identification of themes, categorising information, grouping various pieces of information together and recording observations about the narrative records is a data reduction of qualitative data (Shaughnessy et al., 2003). Coding involves the identification of units of behaviour and antecedents of these behaviours. Learning preferences were identified by indication of what the user liked. Researcher and assistant agreed coding definitions for each category observed. This was based on written definitions indicated prior to the study.

\subsection{Participants}

A purposive sampling was used to recruit participants of unspecified levels of ID. Recruitment was obtained in accordance with ethical standards of the Psychological Society of Ireland (PSI), Department of Psychology and Technology Ethics Committee (DTPEC) and Carmona House Services (CHS). Inclusion criteria specified an ability to communicate verbally and being over 18 years of age. These criteria were established due to lack of additional support from a speech and language therapist. Although five to eight users with ID have been suggested to identify up to $80 \%$ of interface problems (Borsci, Federici, Mele, Polimeno, \& Londei, 2012), this study's sample included 22 participants (9=male, 13=female), between the ages of 19-34 years old $(\mathrm{M}=22, \mathrm{SD}=3.72)$. Levels of ID were not obtained in accordance with Psychological Society of Ireland (PSI) ethics.

\subsection{Accessible Materials for People with ID}

Materials were designed in an easy to understand format inspired by materials designed by Maloney (2012). Tasks descriptions are used throughout development, involving users early in the development lifecycle of interactive products (Rogers, Sharp, \& Preece, 2015). Seven tasks were created to explore the Let's Be Safe application, with progressing difficulty to accommodate levels of ability through four modes of learning (game, video, audio, reading). Categories of usability and engagement were adapted from the DEVAN usability and fun coding scheme (Macedo \& Trevisan, 2013). A self-report Adapted Usability Questionnaire (SUS) collected data on usability, engagement, preference of learning and post intervention learning consisting of seventeen-items; ten Smileyometer-scale questions; one closed question; six open-ended questions; an adapted four-point

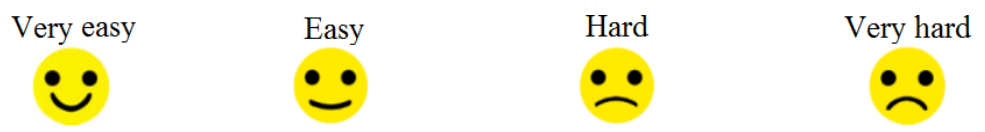

Figure 2. Example of Smileyometer

Smileyometer rating scale was used to limit the cognitive load on participants. Kline (2005) found the Smileyometer-scale to have acceptable reliability, with a Cronbach's Alpha of .706. Reporting for this study focuses on usability, engagement and preference of learning. A Smileyometer is a Likert type scale evaluating people or events of a psychological nature and is often treated as interval data. As distance between each option cannot be measured in this type of scale and may be treated as ordinal data (Shaughnessy et al., 2003). PCs running Windows-10 OS and Chrome browsers were used to run the Let's Be Safe application. A mouse was provided for navigation and headphones were available for each participant. Camtasia screen recording software captured participants' interaction with the application, recording screen activity such as the users' navigation of the interface and errors. 


\subsection{Procedure}

Each session took place in a computer laboratory and was two hours in length. Care staff with whom the participants were familiar accompanied them. The participants completed a demographics questionnaire and support was offered, if the individual asked. Participants received a printed number with instructions. This was used to identify them without using their name and thus protect their identity. All participants sat at a PC with headphones and were given instructions on how to use the task sheets. Researchers reminded participants they were observing how easy the application was to use and not the performance of the individual. Observation based on the codebook lasted 10 minutes. Once complete, the Adapted- SUS was filled out by the individual, with assistance as requested. A debrief form with contact details of the lead researcher was given to each participant to take with them and they were thanked for their contribution to the study.

\section{RESULTS}

\subsection{Analysis Procedure}

A combination of both inductive and deductive approaches of thematic analysis was used in this research study. The advantage of this approach is the integration of themes derived from literature with themes that emerge from the data examined. The observational method of usability evaluation used in the present research focused on usability and emotional response of users during the interaction. Thematic analysis was conducted on the data collected during the observations. Deductive thematic analysis was applied, using a coding frame from the literature. Prior to the data collection process, ten primary themes were identified. Five themes corresponded to usability and five were representative of the emotional response of users. The inductive approach was utilised when analysing the data collected to identify sub-themes.

\subsection{Descriptive Statistics}

22 participants ( $9=$ male, $13=$ female), ranging in age from 19-34 years $(\mathrm{M}=22, \mathrm{SD}=3.72)$ took part in the study. Their use of computers included smartphone, iPad, laptop and PC. Students indicated using the computer everyday $(n=14)$, once a week $(n=7)$, or once a month $(n=1)$. All participants indicated using a computer $(n=22)$ with varying frequency summarized below. Participants reported using the applications Snapchat, Facebook, WhatsApp, Skype, and Facetime. Of those that use Facebook $(n=12), 75 \%$ found it easy to remember their password $(n=9)$ while $25 \%(n=3)$ indicating that it was not easy to remember or that they needed help in remembering their password.

\subsection{Findings}

\subsubsection{Observation of Themes in Engagement and Usability}

Definitions of themes were discussed and agreed by researchers and assistants before observations took place. Observed behaviours indicating each theme were agreed prior to observations. Ten themes were used to observe emotional engagement and usability of participants. Five themes for emotional engagement (task completed/stopped before reaching goal, focused, interested/bored; likes/dislikes; positive/negative vocalisation; positive/negative behaviour) and five themes for usability (errors, assistance, confusion, motor difficulties, perception) were identified. The participants were observed while interacting with the application through seven tasks (task 1 =animation video; task 2= reading; task $3=$ listening to Alice's story about being cyberbullied; task $4=$ watching the video about cyberbullying; task $5=$ reading about online safety and playing the game; task $6=$ watching Strangers and friend video with people; task $7=$ game). Frequency of overall observed positive emotional responses were $22.43 \%$ with $7.22 \%$ negative emotional responses observed.

Observations were carried out to understand where further development and design of Let's Be Safe could increase usability and accessibility while increasing engagement of the learner. Overall, the observed frequency of positive observed usability was $46.85 \%$ and negative was $23.5 \%$. 


\subsubsection{Preference of Learning Modality}

Preference of learning mode in Let's Be Safe was indicated by a four- point Likert type scale (like a lot, like a little, dislike a little, dislike a lot) and a multiple-choice question with six options 'What do you want more of in the app?', with multiple selection options (games, videos with animation, videos with people, sounds/talking, reading, something else). Of the $71.56 \%$ indications for like a lot, the listening activity was reported most frequently with $17.43 \%$, followed by $15.60 \%$ for the game, $13.76 \%$ for the video with animations, $12.84 \%$ for the reading activity and $11.93 \%$ for the video with people.

\subsubsection{Thematic Analysis of Literature and Focus Group}

A question led focus group was conducted at the beginning of each session. The discussion was guided by one researcher while the other researchers and assistants took notes. This focus group gathered information from participants about their knowledge and experience of bullying, cyberbullying and cybersafety. Each focus group consisted of between five and nine participants. Thematic analysis of literature revealed four key issues (vulnerability, safe guarding, emotional impact and need for skill development) faced by adults with ID. These themes were identified within the focus group contributions. Literature revealed $17.86 \%$ occurrences of vulnerability; $8.33 \%$ safe guarding: $30.95 \%$ self-determination; and $42.86 \%$ need for skill development. The focus group results revealed $20 \%$ occurrences of vulnerability, $27 \%$ safe guarding, $31 \%$ self -determination and $22 \%$ need for skill development. The feedback from the focus group supports the research suggesting the need for this population to be informed and educated about cyberbullying and cybersafety. The majority of participants had seen cases of bullying or cyberbullying while some disclosed having personally experienced victimisation. Key themes from literature explored in the focus group contributions revealed participants expressed different needs and abilities than indicated by the research, with self-determination occurring most frequently, followed by safeguarding, the need for skill development and vulnerability respectively. This compared to the literature, where the need for skill development occurred most frequently, followed by self-determination, vulnerability and safeguarding respectively.

\section{DISCUSSION}

Observations used to identify occurrences of positive and negative emotional engagement while engaging the Let's Be Safe application revealed positive emotional responses were more frequently observed than negative emotional responses. Adapted SUS self- report measures indicated participants liked a lot of the Let's Be Safe application, with the listening activity most frequently rated the highest, followed closely by the game activity. Indications of what the participants would like to see more of revealed games and videos with people were most favoured. Overall there was a positive usability experience reported by users. Observations supported these reports with positive observations being reported more frequently than negative occurrences.

\subsection{Strengths and Limitations of the Present Study}

Continuing to work with the users themselves provided a secure working relationship from which to develop an intervention (American Psychological Association, 2018). Inclusion of support workers gave further clarity to the needs of this group. This project allows for a multidisciplinary approach in development process, utilising psychology and technology skills for a unique perspective to research. A major strength is the involvement of individuals with ID in the development process of a system targeting this user group. The quality of data collected during the user testing suggests the importance of involving the target user group in the development process as well as the need for further research with this user group. Another strength of this study is the large number of participants involved in comparison to previous qualitative research within both the population and research topic. A limitation of this research is that the validity of responses is uncertain as it is unknown whether the responses reflect the actual thoughts and experiences of the individuals. Responses collected may be inaccurate due to the tendency of this population to please those perceived as authority figures (Cáliz et al., 2017). A focus group does not allow for in depth understanding of individual experiences that may help understand why participants accept friend requests from public figures. 


\subsection{Future Research}

Introducing levels to the application would allow for age appropriate or stage appropriate skill development to support independence and social interaction. Engagement in the focus group conversations offer insights stimulated by the questions and offer a starting point for research (Coolican, 2004) and a lived experience can come forward in smaller groups (Barrett \& Kirk, 2000). Interviews could provide a richer understanding of the experiences of people with ID that are directly related to bullying and cyberbullying. A semi-structured interview is guided but still informal and can provide "more realistic information on the interviewee's own terms" (Coolican, 2004 p. 155). Audio recording would capture the "exact terms and richness of the interview" (Coolican, 2004 p. 160). Video recording of observation sessions would provide a record of non-verbal communication (Coolican, 2004) and further analysis of responses to the application that are missed through researcher note taking.

\subsection{Conclusion}

As educational psychology is required to consider the strengths of people with ID (American Psychological Association, 2018), the focus group contributions remind us of what these strengths are. We see the difference between the literature and the voices of this group, what they are capable of, with self-determination and choice, avoiding interpretations based on norms (Shogren, et al., as cited in American Psychological Association, 2018). With users as the driving force in development, an application can be well-designed based on identified skills and judgements (Rogers, Sharp, \& Preece, 2015). Understanding users' identified preferences will inform the process of development. This will help to create an appropriate instructional resource intervention with educational value for users with ID, engaging them, to stay safe from traditional bullying and to mitigate against the negative consequences and victimisation of cyberbullying.

\section{REFERENCES}

American Psychological Association (2018). Guidelines for assessment of and intervention with persons with disabilities. Retrieved from http://www.apa.org/pi/disability/resources/assessment-disabilities.aspx

Barrett, J., \& Kirk, S. (2000). Running focus groups with elderly and disabled elderly participants. Applied ergonomics, $31(6)$.

Boland, M., Daly, L., \& Staines, A. (2008). Methodological issues in inclusive intellectual disability research: A health promotion needs assessment of people attending Irish Disability Services. Journal of Applied Research in Intellectual Disabilities, 21.

Borsci, S., Federici, S., Mele, M. L., Polimeno, D., \& Londei, A. (2012). The Bootstrap Discovery Behaviour Model: Why Five Users are Not Enough. Cognitively Informed Intelligent Interfaces: Systems Design and Development: Systems Design and Development, 258.

Butz, M. R., Bowling, J. B., \& Bliss, C. A. (2000). Psychotherapy with the mentally retarded: A review of the literature and the implications. Professional Psychology: Research and Practice, 31(1).

Cáliz, D., Martínez, L., \& Cáliz, R. (2017). Helping people with down syndrome through a usability testing guide proposal for mobile applications. International Journal of Computer Science, Engineering and Information Technology, 7(2), $1-19$.

Coolican, H. (2004). Research methods and statistics in psychology. UK: Hodder and Stoughton.

Creswell, J. W., \& Creswell, J. D. (2017). Research design: Qualitative, quantitative, and mixed methods approaches. Sage publications.

Denzin, N. K., \& Lincoln, Y. S. (Eds.). (2005). The Sage handbook of qualitative research (3rd ed.). Thousand Oaks, CA: Sage.

Dunn, D. S., \& Dougherty, S. B. (2005). Prospects for a positive psychology of rehabilitation. Rehabilitation Psychology, $50(3)$.

Gill, C. J., Kewman, D. G., \& Brannon, R. W. (2003). Transforming psychological practice and society: Policies that reflect the new paradigm. American Psychologist, 58(4).

Gravetter, F. J., \& Forzano, L. B. (2012). Research methods for the behavioral sciences. International Edition: Wadsworth. 
Kline, R., B. (2005). Principles and Practice of Structural Equation Modeling, (4th ed.). Montreal, Canada: Concordia University.

Heber, R. (1961). A manual on terminology and classification on mental retardation (Rev. ed.). Washington, DC: American Association on Mental Deficiency.

Kirijian, A., Myers, M., \& Charland, S. (2007). Web fun central: online learning tools for individuals with Down syndrome. Universal Usability: Designing Computer Interfaces for Diverse User Populations, 195-230.

Macedo, I., \& Trevisan, D. G. (2013, July). A method to evaluate disabled user interaction: a case study with down syndrome children. In International Conference on Universal Access in Human-Computer Interaction (pp. 50-58). Springer, Berlin, Heidelberg.

Moloney, M. (2012). Accessible Information: Advocating the Use of Technology for Individuals with Intellectual Disability on their Path to Individualised Services.

Paine, T. (2009). Virtual violence: protecting children from cyberbullying.

Pallant, J., \& Manual, S. S. (2010). A step by step guide to data analysis using SPSS. Berkshire UK: McGraw-Hill Education.

Rogers, Y., Sharp, H., \& Preece, J. (2015). Experimental design. Interaction Design: Beyond Human-Computer Interaction, 486.

Schalock, R. L., Luckasson, R. A., \& Shogren, K. A. (2007). The renaming of mental retardation: Understanding the change to the term intellectual disability. Intellectual and developmental disabilities, 45(2).

Shaughnessy, J. J., Zechmeister, E. B., \& Zechmeister, J. S. (2003). Research methods in psychology (6th ed). New York, N.Y.: McGraw Hill Higher Education.

Smith, P. K., del Barrio, C., \& Tokunaga, R. S. (2013). Definitions of bullying and cyberbullying: How useful are the terms. Principles of cyberbullying research: Definitions, measures, and methodology.

Sweetman, D., Badiee, M., \& Creswell, J. W. (2010). Use of the transformative framework in mixed methods studies. Qualitative inquiry, 16(6).

Tokunaga, R. S. (2010). Following you home from school: A critical review and synthesis of research on cyberbullying victimization. Computers in human behavior, 26(3). 